\title{
A memória do teatro para além das comemorações
}

\author{
Ana lsabel Vasconcelos
}

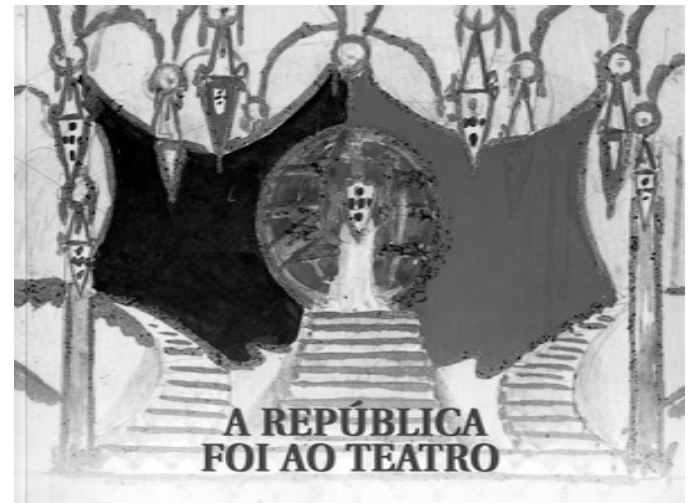

José Carlos Alvarez (Coord.), A República foi ao teatro. Catálogo da exposição, Lisboa, Instituto dos Museus e da Conservação, 2010, $104 \mathrm{pp}$.

Os eventos comemorativos do centenário da República, cujo encerramento formal teve lugar na Assembleia da República no dia 20 de Outubro de 2011, foram oficialmente tutelados por uma Comissão Nacional, encarregue de os preparar, organizar e coordenar através do apoio concedido a grupos e instituições que propuseram iniciativas nesse âmbito. Desta feita se multiplicaram efemérides de indole cultural, merecendo as exposições um lugar de destaque.

A primeira grande exposição de referência, intitulada "Viva a República! 1910-2010", teve lugar na Cordoaria Nacional entre Junho e Outubro de 2010 e destinava-se ao público em geral, evidenciando preocupações pedagógicas na forma como ia apresentando e explicando "os ciclos políticos mais marcantes da história de Portugal no séc. XX". Tratou-se de uma extensa mostra, organizada em núcleos periodológicos, onde se cruzaram materiais preparados para a exposição com documentos da época, numa feliz combinação, assistida por modernas tecnologias. Sendo um evento com enfoque especial nos acontecimentos políticos, o núcleo dedicado às artes e às letras teve uma representação mais contida, o mesmo acontecendo com o espaço dedicado ao teatro.

É conhecida a vitalidade desta arte durante a $1 .{ }^{a}$ República, chegando a estar em funcionamento, na capital, em 1916, uma dezena de teatros, onde se representavam dramas, comédias, operetas, revistas e até um drama policial. Era também usual passarem por Lisboa companhias estrangeiras, que tinham, como cabeça de cartaz, notáveis da cena internacional, sobretudo francesa, com quem ombreavam actores e actrizes portugueses/as, alguns dos quais ainda na memória de muitos de nós. Por tudo isto e porque, desde a sua abertura, se tem dedicado à preservação e divulgação do nosso passado teatral, o Museu do Teatro organizou uma exposição que denominou "A República foi ao teatro", encerrando este título as duas áreas de confluência desta mostra.

A ocupar a galeria de exposições temporárias, já que há algum tempo se optou, e acertadamente, por preencher o edifício principal - o Palácio do Monteiro-Mor -, com uma exposição permanente, o espaço agora disponível não é de grandes dimensões, tendo contudo sido feito um trabalho notável no aproveitamento do mesmo. Embora o propósito deste nosso texto seja fazer uma apresentação crítica do catálogo desta exposição, não podemos deixar de referir o evento que lhe serve mais de motivo do que de referência. Neste sentido, podemos dizer que, apesar da excelência da exposição, o catálogo não tem a preocupação de a reflectir tout court, sendo a publicação sobretudo dedicada a textos de reflexão, estes da autoria de especialistas, que nos vão revelando e explicando aspectos vários do fenómeno teatral durante o período em apreço.

A exposição propriamente dita é-nos apresentada, neste catálogo, pelo director do Museu, José Carlos Alvarez, principal responsável pela iniciativa e coordenador desta publicação. Optou-se por uma edição em papel couché, num formato horizontal, de 28,5 por $22 \mathrm{~cm}$, o que propiciou a combinação entre o texto e as imagens e uma articulação entre a ilustração e a palavra, num resultado conteudisticamente esclarecedor e esteticamente feliz. Todos os documentos da exposição, alguns dos quais reproduzidos no catálogo, pertencem ao arquivo do próprio Museu, que tem recebido doações de espólios de importantes personalidades da vida teatral portuguesa e de algumas companhias, ascendendo hoje a vários milhares os documentos que tem à sua guarda.

Numa breve introdução institucional, a direcção do Instituto dos Museus e da Conservação apresenta, de uma forma sinteticamente esclarecedora, o propósito da exposição:

A exposição [...] interpreta e evoca o ambiente teatral, num quadro social, estético e político, caracteristico da Lisboa pré- e primorepublicana (de 1908 a 1916), propondo-se também questionar se os primeiros anos da República, constituindo momentos históricos de ruptura política e de grande tensão social, propiciaram, ou não,
Ana lsabel Vasconcelos é professora da Universidade Aberta e investigadora do Centro de Estudos de Teatro da FLU. Entre os livros que publicou sobre a História do Teatro Português contam-se $O$ teatro em Lisboa no tempo de Almeida Garrett (Lisboa, Museu Nacional do Teatro, 2003), $O$ drama histórico português no século XIX (183656), (Lisboa, FCT/Fundação Calouste Gulbenkian, 2003) e, em coautoria com Ana Clara Santos, Repertório teatral na Lisboa oitocentista (18351846), (Lisboa,

Imprensa NacionalCasa da Moeda, 2007) e Repertório teatral na Lisboa oitocentista (1846-1852), (Lisboa, Imprensa NacionalCasa da Moeda, 2011). 
Caricatura do actor

Augusto Rosa (1852-1918), da autoria de Amarelhe [Cortesia do Museu Nacional do Teatro]. O pão nosso, Teatro da

República

[Cortesia do Museu Nacional do Teatro alterações estruturais ou movimentos de renovação estética no que concerne ao meio teatral português, considerando o teatro como um terreno artistico potencialmente vocacionado para a renovação (p. 7).

Esta questão tem servido de matéria de investigação e reflexão a alguns estudos sobre o teatro acontecido

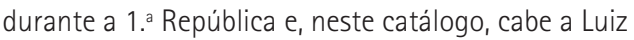
Francisco Rebello responder a esta interrogação, num longo e sustentado artigo intitulado "O teatro na transição do regime (1875-1876 a 1917-1918)". Assumindo que o "teatro é, por excelência, o lugar da História, o cadinho em que se fundem e confundem os destinos colectivos e individuais, as angústias, os sonhos, as frustrações, de todos e de cada um" (p. 65), este historiador do teatro português apresenta-nos os principais autores e textos que foram escritos e representados neste período, antecedendo-os de uma esclarecedora contextualização histórica. Através de uma apresentação diacrónica, contactamos com inúmeras peças, associadas a tendências estéticas que se foram sucedendo, mais num movimento de continuidade do que com processos de ruptura. Rebello assinala, contudo, momentos de inovação estética, que conviveram com um teatro que estagnara, "numa rotina que teimava em conservar as relíquias do romantismo e raramente transcendia os limites de um realismo superficial" (p. 79). Refere-se aqui ao Teatro Livre (1904) e ao Teatro Moderno (1905), duas iniciativas que considera como as tentativas mais sistemáticas de implicar o teatro no derrubamento da monarquia. 0 subcapítulo especificamente dedicado aos primeiros anos da República termina com a evocação dos actores e das actrizes que, "emprestando o seu corpo e a sua voz às personagens ideadas pelo dramaturgo, permitem à obra teatral perfazer o seu destino" (p. 90). A fechar o artigo, destaque ainda para o teatro de revista, assunto que Rebello retoma de outras publicações, aqui acompanhado por fotografias de cena.

Como acima referimos, para além de Luiz Francisco Rebello, outros especialistas colaboraram neste catálogo com textos que reflectem sobre aspectos elucidativos do ambiente teatral da época. São eles: Osvaldo Macedo de Sousa, que se dedica à caricatura teatral, Paulo Baptista que trata da fotografia teatral, e Gonçalo Antunes de Oliveira, que retoma a temática do teatro de revista, apresentando-a numa perspectiva diversa. Este último investigador disserta sobre este sub-género teatral que "constituiu um produto cultural gerado por uma Indústria
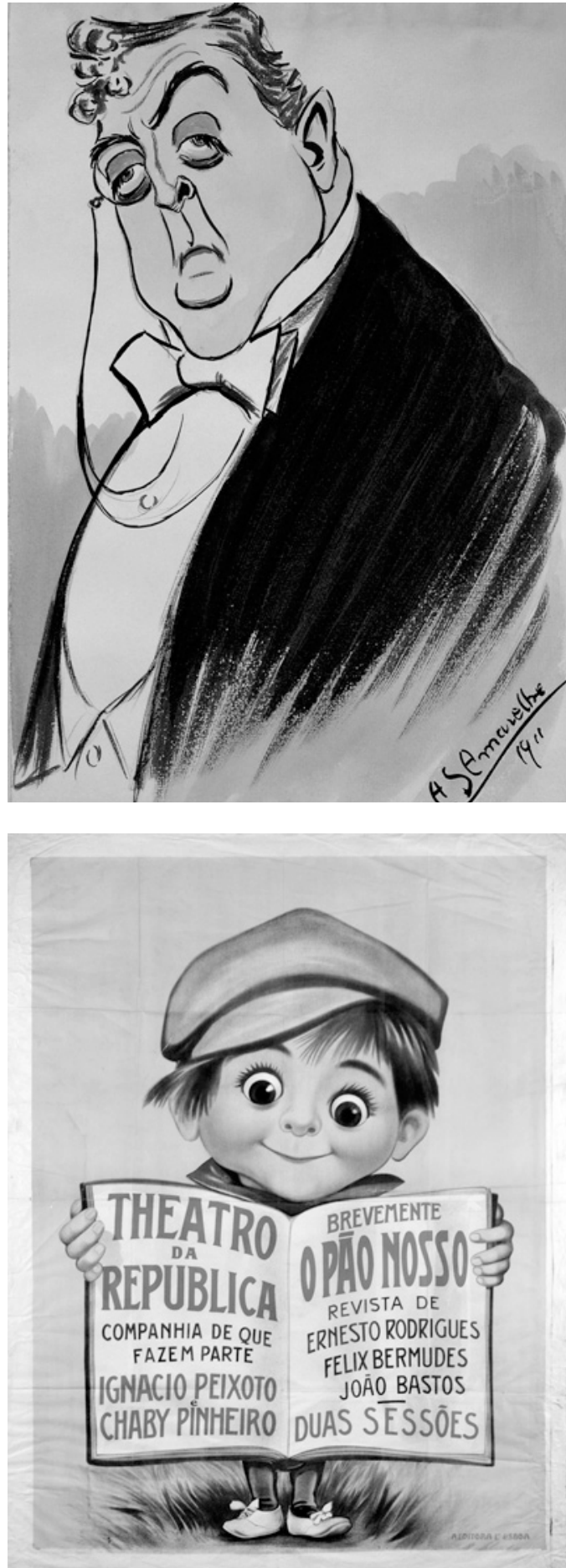

do Entretenimento e difundido transversalmente entre os vários media [...], de que resultou a criação de uma rede de produtos com grande proximidade junto dos consumidores" (p. 28). Refere-se Gonçalo de Oliveira especificamente à componente musical, que, autonomizando-se, teve um impacto que foi muito para além do momento da representação e para o qual este investigador chama a nossa atenção (cf. p. 26). 0 elemento tradicionalmente valorado no teatro de revista, nomeadamente no periodo da República, diz respeito à sua perspectiva crítica relativamente à sociedade coeva, procurando-se normalmente avaliar o lugar que ocupou e a função que desempenhou naquele contexto político, 


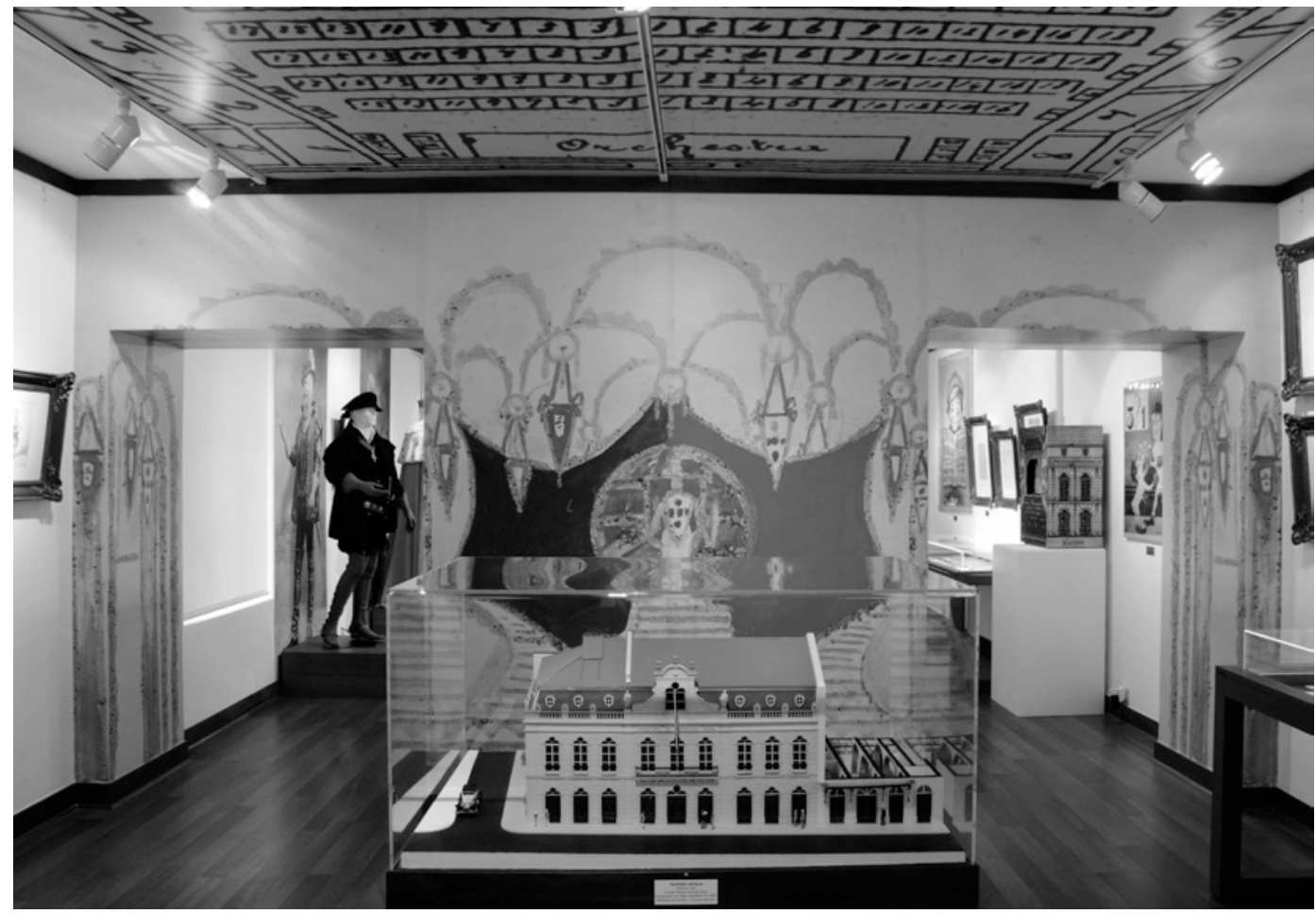

cultural e social. Para tal e, como reconhece o investigador, para se ir mais além no estudo deste tipo de manifestação espectacular, há que o fazer aplicando "modelos operatórios que fujam à mera enumeração factual", proporcionando uma "interpretação histórico-cultural que dê sentido à variedade assimétrica dos textos que chegaram até nós" (p. 35).

A fotografia é um contributo inestimável para a preservação das memórias teatrais, sobretudo a partir do último quartel do séc. XIX, e, como nos explica Paulo Baptista, já muito antes a cenografia teatral se servia de alguns dos mesmos princípios ópticos para criar efeitos que pudessem surpreender o espectador (cf. p. 39). Num artigo intitulado "O Teatro e a fotografia no tempo da República", este investigador explica-nos a importância e o impacto do "retrato encenado" na divulgação do trabalho do actor, consistindo aquele novo produto na reprodução das "mais representativas poses do actor, retiradas das cenas mais marcantes das peças de maior sucesso na sua carreira" (p. 40). Estas imagens começam a ser reproduzidas em publicações de grande circulação, como a llustração portuguesa, que, ao longo de diversos números, ilustra as biografias de actores e actrizes com fotografias produzidas pelos mais prestigiados estúdios de Lisboa. Numa abordagem sobre as relações entre esta nova arte e outra bem mais antiga, o teatro, Paulo Baptista vai apresentando diversos produtos que nasceram desta intersecção, desde a edição de postais de artistas até fotografias de cena, graças às quais podemos hoje, e em especial nesta mesma exposição, resgatar imagens de uma arte que é, pela sua condição, efémera.

Uma penúltima palavra para as magníficas caricaturas deste catálogo, aqui apresentadas, explicadas e

contextualizadas por Osvaldo Macedo de Sousa, no artigo "A caricatura, o teatro e a República". Intimamente ligada ao humor, a caricatura encontrou no teatro um terreno fértil, destacando-se, no período final da monarquia, o traço de Bordalo Pinheiro, a quem se devem publicações que hoje muito nos ajudam a recuperar aspectos de pormenor sublinhados pela própria iconografia. Mas - até por razões históricas, por Bordalo ter falecido cinco anos antes da implantação da República - é a Amarelhe que Osvaldo Macedo rende homenagem, considerando-o responsável pela grande "revolução" na caricatura teatral da primeira República (cf. p. 60). Acompanhando o percurso biográfico deste grande caricaturista, passam-se em revista as diversas facetas das suas produções, que tiveram 0 meio teatral como tema de eleição: "Na sua pena ficaram registados, para a eternidade, todos os mestres, todas as vedetas, todas as pessoas que no teatro mereceram o seu aplauso caricatural" (p. 62).

Referimos, por último, a intervenção de José Carlos Alvarez. Num texto inicial que glosa o título da exposição, o director do Museu apresenta a composição dos vários núcleos temáticos - espaços teatrais, repertórios, actores e actrizes, periódicos e outras publicações, trajos e adereços de cena -, não sem antes nos anunciar claramente o seu propósito fundamental:

[...] através de um conjunto de fragmentos e vestigios de natureza e origem diversa, mas todos contemporâneos dos últimos anos da Monarquia e dos primeiros anos da República, dá-se notícia e informação sobre a vida teatral desse agitado e marcante periodo da nossa História e do papel e da importância do teatro durante aqueles anos, e vice-versa, ou seja, de que forma o teatro foi ou não contaminado (dos pontos de vista estético e político) por estes ideais revolucionários e republicanos (p. 14).

Embora terminado o ano do centenário da República, é ainda possivel aqui "visitar" a vida teatral das primeiras duas décadas do séc. $X X$, apreciando um vasto conjunto de materiais criteriosamente escolhidos e exibidos de forma sedutora. Exposições como esta devem permanecer para além de todas as comemorações. 